\title{
Design on English Word Library Management System based on PHP Technology
}

\author{
Mingjie Wang \\ College of Foreign Languages, Bohai University, Jinzhou, 121013, China \\ 1834078850@qq.com
}

Keywords: English word; management system; PHP technology; learning strategy; database design; function design

\begin{abstract}
Mastery of the vocabulary of a direct impact on the English listening, speaking, reading, writing and translation capabilities, there is no accumulation of words, cannot learn the language. In this paper, presents the English word library systems based on PHP technology, system stored massive vocabulary, learners through English words, sentences and related phrases learning, improve the efficiency of learning vocabulary. Firstly, the English word library system using PHP technology and working principle of PHP technology; then, elaborated database design, introduces the selected database MySql, the importance of database design, and the main data tables: the definition and description of vocabulary table; Finally, introduces the main function of the system, including online and offline queries, Chinese to English, English to Chinese, the word test, word games, and so on.
\end{abstract}

\section{Introduction}

With the rapid development of computer technology and network technology, the network learning has become a very common thing. The network environment has become a part of people to study, work and life of the indispensable. Of course, learning English is no exception, English as the common language of the world's people to communicate, is the world's most extensive range of applications language. Such as network addresses, email addresses. These are all from English composition. But how to quickly and efficiently learn English is a required question worth pondering [1]. Traditional English word learning mode has been unable to meet the new needs of social development, multimedia computer assisted language learning with its unique advantage has become a new English learning mode.

At present, most English learners such as students, they tend to learn English by reading book. This paper studies English word library system based on PHP technology. The system includes the rich content and a lot of vocabulary, gradually increase the degree of difficulty, suitable for most people to learn. Show a large vocabulary and detailed explanation. Have learning, practice and evaluation in the process of English learning. This system will not only learn, practice, and evaluation of combined seamlessly, while providing situational dialogues and word games. To stimulate students' interest in learning, so that make the boring English words learning becomes lively and interesting. Multiple perspectives improve the efficiency of learning English, to provide a comfortable and enjoyable learning atmosphere. The combination way of practice and experience enhanced user's interest in learning English. Thus, such a system is necessary.

\section{Learning Strategy}

Strategy is used in the field of education to become a learning strategy, which is to make learning easier, more effective, more independent and more specific action to be taken, is a scientific and efficient way of learning, including three factors: First, clear learning objectives and adopt a proactive attitude towards learning; the second is to select, applying appropriate learning methods; the third is effectively self-monitoring. The use of learning strategies is not only related to the learner's cognitive, but also too many other aspects of learners. Learning strategy is not always explicit, but learners usually perceive their own learning strategies; and the selection and 
application of learning strategies will change with the environment impact [2].

The influence of learners on learning strategy selection includes two factors, one is the learner's personal factors; the other is social and environmental factors [3]. Personal factors of learners, the differences among the learners are in several aspects, such as attitude, ideas, feelings and personal factors. The first is the learner's view and focus on learning language. If learners pay more attention to language learning, they will use more cognitive strategies and memory strategies to understand and memorize the contents of language learning. If learners pay more attention to language functions, they use less cognitive strategies, memory strategies and other strategies, and more use of communication strategies. Social and environmental factors, includes the learning language, environment of learning language and learner facing learning tasks. In learning some language, the learners use more strategies than others. For the United States to learn the second language learner survey found that the use of learning strategies for learning Spanish learners was less than that of French or German learners. Commonly used English vocabulary learning strategies include:

(1) The dictionary strategy. Dictionary is the most important reference book for language learners. Dictionary provides detailed information of words: word pronunciation, part of speech, meaning Chinese or English interpretation, etymology, common phrases, usage, example sentences, compound words, antonyms, synonyms, semantic, stylistic, British English or American English, style and so on. If you can make full use of the dictionary information given, can be more comprehensive grasp of a word usage.

(2) Chunks strategy. Lexical memory strategy is students to vocabulary sound, form, meaning, their characteristics and their existing knowledge and experience, through a variety of ways in the word association tone, shape, establishing a link of the various images betweens words, so that old and new knowledge organically linked to form a new method of memorizing vocabulary or larger chunk of vocabulary.

(3) Context strategy. In language learning, to follow the rule of "the words not leave word, words not separated sentences, sentences not separated piece". There are a wide variety of language functions, each function in specific contexts to be reflected. Similarly, the vocabulary is also present in context. Context includes talk time, place, surroundings, method of communication between speaker and hearer and so on.

(4) Voice strategy. In the English language system, there is a mutual relationship between pronunciation and spelling. If the student has relatively systematic understanding for English pronunciation, it can help students to remember the spelling. Through the mastery of English pronunciation, auxiliary students spell out the correct alphabetical order. Once the students attach importance to the system to master vocabulary pronunciation, and then go to the memory of the words can receive better results.

\section{Main Technology}

PHP (Hypertext Preprocessor) is an easy to learn and use server side scripting language, is one of the tools to generate dynamic web pages. It is a scripting language embedded in HTML files. PHP syntax own mixed C, Perl and Java syntax, and formed its own unique style; the goal is to make Web programmers to quickly develop dynamic web pages. It is today the most popular internet scripting language [4]. PHP has the following characteristics: simple grammatical structure, application program development fast, run fast, technology itself is fast learning; powerful database support (such as: ORACLE, DBASE, MySql, INTERBASE); function is powerful; and compared to other technologies, PHP itself is free and code is completely open; code execution efficiency is high, consume considerably less system resources (especially for MySql database access, very direct, concise, no additional overhead) [5]; cross-platform is strong, because PHP is often used as a server-side scripting, almost can be used on any platform, such as Linux, Windows, in addition, the easy portability between the various platforms also allows development to become more convenient. Do technical supports of word library system is based on such language and database technology, easy to query, modify, and well adapted to the word library openness and confidentiality. The working process of PHP is shown in Fig. 1. 


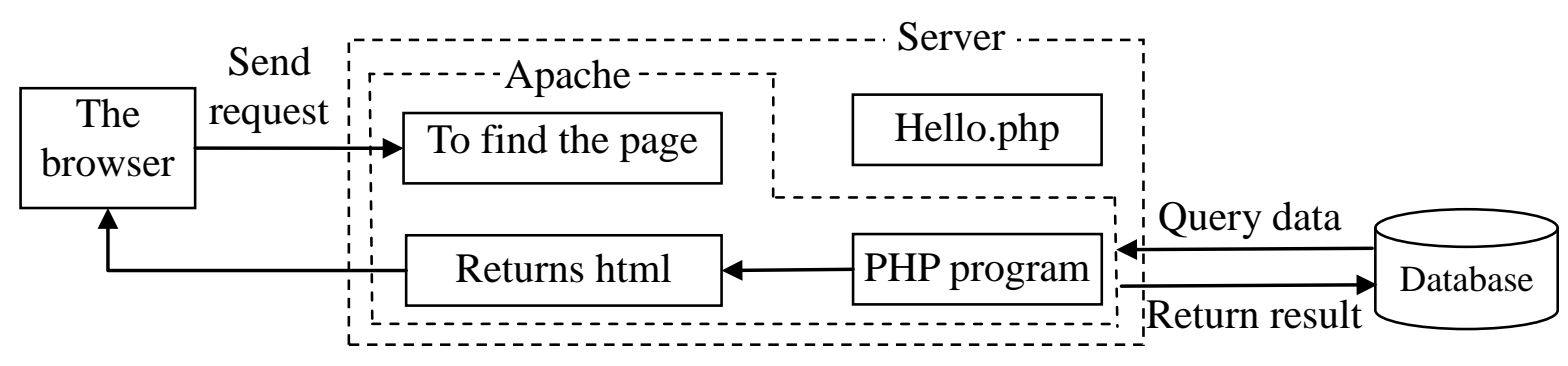

Fig. 1. PHP work flow chart

Run the PHP, usually used Apache as Web server, MySql database. The working principle of PHP [6]:the user through the browser to the Web server sends the page or page part data request; Web server analyzes the request, transferred to PHP procedures to process; PHP recall the content that the user requests access to, connect to the database and query other relevant data; database return query results, returned to the PHP program; PHP processing query results, the result and the user requesting access to the corresponding page is sent to the Web server together; Web server will PHP return the data and the corresponding pages into a static HTML format is sent to the user's browser, the user's browser interpreting and executing, while displayed on a user' page.

\section{Logical Structure Design of the Database Table}

According to the characteristics of PHP, PHP can be compiled into has the function which connects with many database. PHP and MySql is perfect combination [7]. In addition, it is also possible to can also write your own external function to take indirect access to the database. By this way, when used database needs to be replaced, you can easily change the coding to accommodate this changed. This article selects MySql as database.

Table 1. Vocabulary table

\begin{tabular}{c|c|c|c|c|c|c|c}
\hline $\begin{array}{c}\text { Fields } \\
\text { NO }\end{array}$ & $\begin{array}{c}\text { Fields } \\
\text { Name }\end{array}$ & $\begin{array}{c}\text { Fields } \\
\text { Type }\end{array}$ & $\begin{array}{c}\text { Fields } \\
\text { Width }\end{array}$ & $\begin{array}{c}\text { Fields } \\
\text { NO }\end{array}$ & $\begin{array}{c}\text { Fields } \\
\text { Name }\end{array}$ & $\begin{array}{c}\text { Fields } \\
\text { Type }\end{array}$ & $\begin{array}{c}\text { Fields } \\
\text { Width }\end{array}$ \\
\hline 1 & WordID & Ineger & 4 & 8 & Example & Nvarchar & 200 \\
\hline 2 & Meaning & Nvarchar & 50 & 9 & Essay & Nvarchar & 500 \\
\hline 3 & Spell & Nvarchar & 50 & 10 & ReID & Integer & 4 \\
\hline 4 & Phonetics & Nvarchar & 50 & 11 & ReWord & Nvarchar & 50 \\
\hline 5 & Pronunce & Nvarchar & 50 & 12 & RePhonetics & Nvarchar & 50 \\
\hline 6 & $\begin{array}{c}\text { Part of } \\
\text { speech }\end{array}$ & Nvarchar & 50 & 13 & ReMean & Nvarchar & 50 \\
\hline 7 & Phrases & Nvarchar & 100 & 14 & RePhrases & Nvarchar & 100 \\
\hline
\end{tabular}

MySql is a relational database management system, relational database to store data in different tables, rather than putting all the data in a large warehouse, thus increasing the speed and improved flexibility. SQL language used by MySq is the most commonly used standardized language for accessing databases. MySql software because of its small size, high speed, and overall has a low cost. MySql is a relational database of open source code, with the majority of the characteristics of a large database, its design is well suited for managing many Web database applications program, and provides a large number of the client interface of programming languages (such as Perl, C, PHP), the query speed and other operating speed is very quick [8].

Database design for system development has an extremely important influence, database design directly determines whether the stable operation of the system and whether it has good scalability. In the entire database design process, always follow the principles of database design standardization and regulation, on the basis of fully reflects the needs of the system, to ensure the 
accuracy and consistency of the data [9]; improve the efficiency of data query through the way of reasonable table structure. In this paper, the database tables are: user information table, answer table, the user's word table, vocabulary table, and so on. The definitions and descriptions of vocabulary table are shown in Table 1 . Vocabulary table is mainly used to store word information; the field mainly includes the number of words, meaning, spelling, phonetics, pronunciation, part of speech, phrases, example, essays, related words, related words phrases, sentences and other related words example.

\section{Functional Design}

English word library system administrators to query, add, modify, and delete, system update and maintenance operations. Users can query, study, test and other functions. Functional module diagram of the system is shown in Fig. 2. The main function of the system is described as follows:

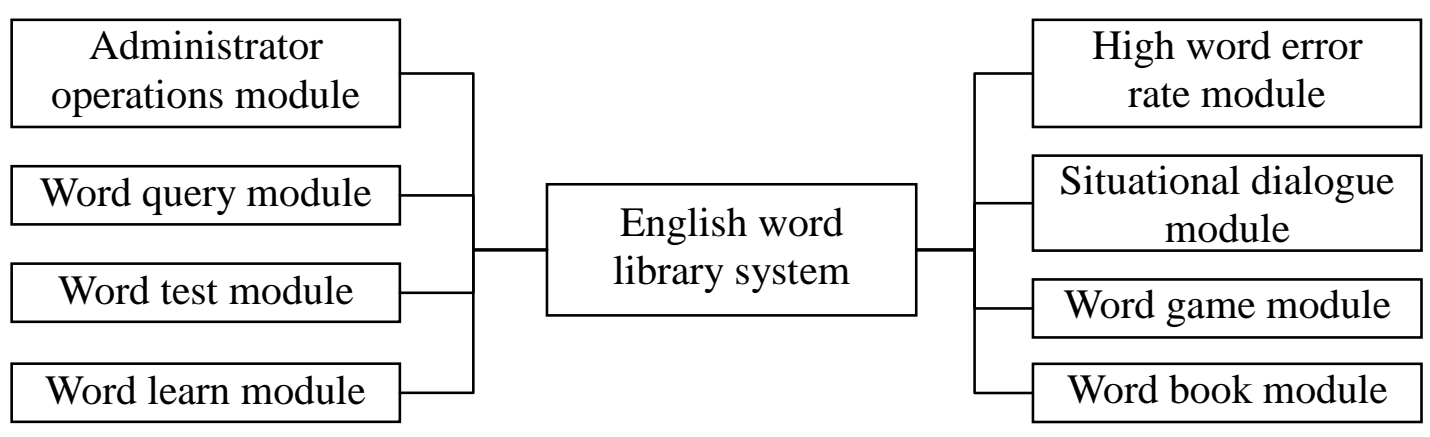

Fig. 2. English word library system function module

Word query module: This module is divided into local queries and network query in two ways, can be divided into Chinese to English and English to Chinese. First, the English word library system default for local queries, enter the English word or Chinese words that user want to query, the server by passing parameters in the database search, feedback to the user and displayed on the current page. When the query is successful, displays the current meaning of the word, phonetic, related phrases, and words that match the pictures and sentences, phrases and words associated with the word sentences, users can also learn the pronunciation of words by sound button [10]. User can also enter a dialogue scene mode to achieve the expansion of knowledge points. When local query without result, the need for online inquiries in the case of network connection. Can also be added to the query word in this word, the word book displays the user to add the word, in a word query and word learning interface can be added to this word, and easy to learn later deepening study. Users can add the required new words, in the word book for word can add and delete operations.

Word learning module: according to the needs of software oriented groups, design word learning module. It divided into primary, junior high school, high school, CET4, CET6, IELTS, TOEFL and so on. User can choose different levels of learning. Through word dictation and the text, read aloud, word repeat words and many kinds of ways to practice; when mastered can be entered into the word test module.

The word test module: This module provides different kinds of grades word library, such as: primary, junior high school, high school, CET4, CET6, TOEFL, IELTS and so on. Can be tested according to alphabetical order, is a combination of word order in accordance with the first letter of the word in order to carry out. Each group of words is all words beginning with that letter within the semester students selected. For example, choose a seventh grade student last semester, select the first letter B, then the system will give the semester all words beginning with $\mathrm{B}$ in seventh grade. After completing this group of words, users can reselect according to their needs another way to learn words or word test. Other way: by part of speech to test or error frequency to test [11]. When the user submits the answers, the system will score the answer made to user, the user answered incorrectly recorded words. Records the total number of learning vocabulary, proportion of the learning vocabulary in the total number of words library; learning outcomes for each phase include 
daily or weekly number of learning new words [12]. System adds to the word of high word error rate into word book.

Situational dialogue module: user learning a word, can enter the word suitable for the scene dialogue. The user can also choose own need dialogue in all situational dialogue. After user selecting, sends a request to the server, if the request response is successful, users need to situational dialogue content is displayed on the page. The system also provides game module of learning words, user learning fatigue, according to the word games learning.

\section{Conclusion}

Word memory is a basic requirement of learning English. The traditional word learning tool is mainly used the word manuals, textbooks, dictionaries and other paper resources. Only in accordance with a fixed word order linear learning, cannot interact with any other resources, but not for learning characteristics of learners and make the appropriate adjustments and feedback. The use of English word library system, so that users can choose different ways of learning English vocabulary, the user can put the unfamiliar word added to the word book, can also learn this words related phrases, sentences and essays, but also situational dialogues. Not only expanded the number of English vocabulary, but also to listening, speaking, reading and other comprehensive English ability level is improved, to improve the convenience and efficiency of vocabulary learning.

\section{References}

[1] Q. Y. Zhang, "The Design and implementation of English Vocabulary Learning System," Jilin University, 2014.

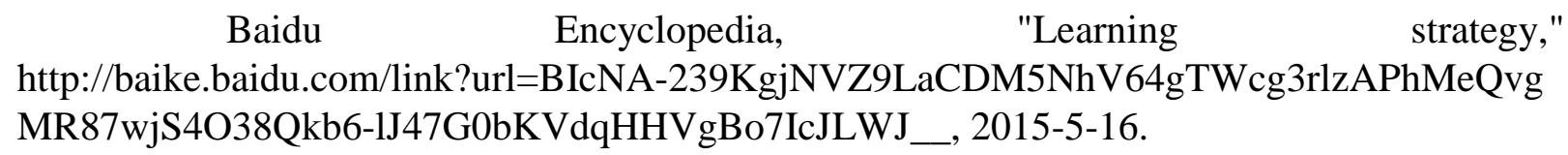

[3] 360doc personal library, "English Vocabulary Learning Strategies," http://www.360doc.com/content/10/0602/23/1301744_30960965.shtml, 2015-5-16.

[4] W. Hu, "Research and Implementation Online Answering System Based on PHP," East China Normal University, 2008.

[5] Y. K. Yu, "Implementation on Intelligent Logistics and Picking Platform Architecture Based on PHP," Southwest Jiao Tong University, 2014.

[6] M. Yang, "Research and Development of the Network File Management System Based on PHP Technology," Hubei University, 2013.

[7] Y. J. Zhang, "The Design and Complementation of the Chinese Learning Website Based on PHP Technology," East China Normal University, 2010.

[8] H. X. Quan, "Design and Implementation of Online Test System Based on PHP Technology," Inner Mongolia Science Technology and Economy, vol. 18, no. 12, pp.81-83, 2006.

[9] L. Wang, Q. Z. Wang,"Design and Implementation on English Vocabulary Learning and Test System Based on .Net," Silicon Valley, vol. 8, no. 2, pp.60-61, 2009.

[10] C. Z. Zhao, "The Design and Implementation of Uyghur-Chinese Multimedia Electronic Dictionary Based on Android Platform," Xinjiang University, 2013.

[11] C. Gong, "Design and Implementation of English M-learning Based on 3G Technology," Northeast University, 2010.

[12] F. F. Xv, "Design and Implementation of Word Learning System Based on Android Platform," East China Normal University, 2013. 